[Philips, D. (2007). The Contribution of Research to the Review of National Qualifications Policy: The Case of the National Certificate of Educational Achievement (NCEA). New Zealand Annual Review of Education, 16, 173-191]

\section{The Contribution of Research to the Review of National Qualifications Policy: The Case of the National Certificate of Educational Achievement (NCEA)}

\section{DAVID PHILIPS}

\section{Abstract:}

New Zealand has implemented a major reform of secondary qualifications since 2002. This has attracted interest in the United Kingdom, Australia, South Africa and elsewhere. It is a standards-based system, whereby learners meet explicit "standards" (statements of knowledge and behaviour and assessment criteria) to gain national qualifications. Secondary students now gain credits towards the National Certificate of Educational Achievement (NCEA). The introduction of the NCEA by the New Zealand Qualifications Authority (NZQA) has been contested, but following government reviews of the conduct of the 2004 national secondary examinations, changes were introduced for the 2005 examinations, and further system review, research and technical monitoring are underway. The purpose of this article is to analyse how research on the NCEA using multiple sources of enquiry has contributed towards understanding its impact on learners, teachers and parents. It concludes with a consideration of some ways in which its implementation might be improved, and raises possible issues for any future review.

n recent years, many countries have looked to qualifications frameworks and/or reforms of their senior secondary certificates as a means of improving the alignment of the multifarious range of qualifications available within a country, matching more closely what

\section{David Philips}

learners need to know prior to leaving school with economic and social goals, and comparing expected levels of achievement across qualification both within and between countries. Global "imperatives" in qualifications reform mean that many countries and regions are investigating ways of modifying their qualifications and certificates (Australian Council for Educational Research, 2006; Donn \& Davies, 2003). New Zealand established its National Qualifications Framework (NQF), a unified framework of nationally recognised qualifications, in 1991, and about ten years later produced a new secondary school qualifications system (the National Certificate of Educational Achievement or NCEA) as part of the NQF (Philips, 2003).

This article will focus on how information about the NCEA is being collated and how this information can contribute towards evaluating the efficacy of the NCEA, within the context of global qualifications reforms. Inevitably this also raises questions about the most appropriate ways of conducting research on national qualifications policies, including reforms of school leaver certification, as part of the more general enterprise of evaluating the effectiveness of national education policies (Philips, 2005; Whitty, 2006). What follows is not intended to be a formal evaluation of the efficacy of the country's secondary qualifications policy, leading to conclusions about whether it "works" or does not work. This remains the responsibility of the New Zealand Ministry of Education. Nor is any attempt made to present a proposal to replace the NCEA. Instead, this article takes the view that any long-term "solution", a viable and valued set of qualifications for school leavers, likely to be readily accepted by all participants in the education system, will require a sustained engagement between researchers and policy makers, and critical discussion of findings from the related threads of enquiry.

Global Developments

Recent reports have provided further evidence of the growing interest worldwide in the development of national qualifications frameworks (Young, 2005). While this phenomenon has been especially evident in English-speaking countries such as Scotland, Australia, New Zealand and South Africa, and more recently England, Wales and Ireland, the European Union has been exploring ways of encouraging its member countries to con tribute to the development of a European Qualifications Framework. They cover the whole range, from those with frameworks in one or more sectors, to those that have hardly begun the journey (Raffe, 2005; Coles, 2006). Such frameworks serve a variety of purposes, 
such as defining common components of qualifications, helping to align a multiplicity of qualifications by showing how they relate to each other in terms of outcomes and levels, encouraging coherence between different types of educational providers and pathways or tracks. The trend, however, should not be interpreted uncritically as indicating that such frameworks in and of themselves necessarily provide solutions to national or regional economic or educational issues, such as promoting lifelong learning, or reducing barriers to gaining qualifications, nor that the process of developing a framework is without its challenges (Young, 2005).

Many countries have also been revamping the ways in which they certify students' achievement in the senior secondary school. In Australia, while each state has its own school leaving certificate(s), most have been moving towards more clearly defined outcomes-based or standards-based approaches. Some recent reviews (e.g., Queensland, South Australia) are proposing new types of certificates based on the notion of students gaining credits. National developments are also underway, such as the proposal for an Australian Certificate of Education (Australian Council for Educational Research, 2006). In the United Kingdom, Scotland took the first steps towards making better links between academic and vocational learning for secondary students, and defining secondary and tertiary qualifications as part of a common framework. England and Wales have introduced new qualifications (e.g., the WelshBac) and a wider variety of certificates aimed at encouraging students who traditionally may not have remained at school to continue studying. This trend is also apparent in New Zealand, where many schools offer students the opportunity to gain qualifications in addition to the NCEA (Pilcher, 2006a, 2006b).

Generally, the qualification(s) available to secondary students are classified as being at the first two or three steps of a country's qualifications framework. However, what happens in the secondary school is often regarded as detached from later learning, and sometimes the various pathways or options available are not well integrated. This is particularly likely when there is a sharp divide between programmes designed for students who are preparing for university entry, and students heading for other destinations, such as other forms of tertiary education, or the workforce.

New Zealand is interesting in this regard, with initial development of a national qualifications framework proceeding at a rapid pace in the early 1990s. This development, based largely on the Scottish approach of the late 1980s, attempted to integrate all qualifications within a common framework based on "unit standards". A unit standard defined a component of any given qualification and how it was assessed, but could also be used across different qualifications. Students were assessed as "competent" or "not yet competent" (a binary distinction). This was followed in the later 1990s by the development of a modified structure, partly in recognition of the fact that universities were not willing to become part of the National Qualifications Framework, with many staff considering that unit standards were an inappropriate way of recognising student achievement in academic areas of learning. This led in turn to the development of the Register of Quality Assured Qualifications to incorporate national qualifications that were not part of the NQF.

Accordingly, a new suite of secondary qualifications based on the New Zealand curriculum was developed with "achievement standards" providing a means for recognising different levels of student achievement, rather than the original binary unit standards (Philips, 2003). The local reasons for, and international influences on, New Zealand's changes in secondary qualifications have been reported elsewhere (Philips, 1998; Strachan, 2001). However, given that New Zealand appears to have progressed further than other countries in developing a unitary qualifications framework, and in linking secondary qualifications into this national framework, it is now timely to explore its impact. This article attempts to do this, using an evaluation framework that incorporates discussion of some of the aspects that have attracted regular comment and criticism (see Zepke et al., 2006).

\section{Developments in New Zealand}

\section{Historical summary}

The NCEA is a qualification registered on the National Qualifications Framework (NQF). It is available at three levels: NCEA Level 1, which is a Year 11 qualification; NCEA Level 2, a Year 12 qualification; and NCEA Level 3, a Year 13 (final secondary) qualification. Students do not necessarily complete the qualification in the Year level stated. Since 2004, school leavers have presented results related to the NCEA and other nationally registered qualifications to gain entrance to university. These results are gained through nationally registered unit standards and achievement standards, both of which have specified learning outcomes and assessment criteria. All standards are assigned a credit 
value, which represents the extent of learning involved. Credit is awarded in each standard when the required level is achieved. High performance may be recognised in achievement standards through merit and excellence levels. Results for unit standards are reported as achieved credit only. Assessment for the NCEA is both internal, or school-based, and external, through examination s conducted by NZQA. These are generally written examinations, but for some subjects are based on inspection of portfolios of student work. A full year's study in a subject is represented by standards totalling between about 20 and 24 credits. Each subject grouping includes both internally and externally assessed standards, but all unit standards are internally assessed.

Students build upon NCEA Levels 1 and 2 to achieve NCEA Level 3 , which is designed to acknowledge achievement across a range of learning areas in the New Zealand curriculum and provides an advanced foundation for further study or employment. Students certified at Level 3 are identified as having the knowledge and skills to solve unfamiliar problems; access, analyse and use information effectively; and work independently. All NCEA awards are gained by accumulating credits. Level 3 requires a minimum of 80 credits, 60 of which must have been achieved at this level, and 20 at Level 2 or above. The NCEA Level 3 replaced the University Entrance Bursaries and Scholarship award in 2004.

\section{Developments since early 2005}

Even before the start of the implementation of the NCEA in 2002 (i.e., Level 1 for students in Year 11), concerns had been raised about the likely impact of the NQF - which had been progressively implemented since 1992 - on secondary schools (Philips, 1998; Lee \& Lee, 2001). These concerns reflect the likelihood of more intensive assessment, possible fragmentation of teaching and learning due to the assessment approach required, an associated increase in teacher workload, and a potential "dumbing-down" of the curriculum linked with the aim of keeping more students at school. This was perceived to be the consequence of using standards for certifying achievement in both "academic" and "vocational" subjects or areas of learning, which most senior secondary school students could gain through multiple attempts.

It is nearly two years since the New Zealand Government released its Report on the Performance of the New Zealand Qualifications Authority in the Delivery of Secondary School Qualifications by the Review Team led by Doug Martin (State Services Commission, 2005,
July). This included a large number of recommendations aimed at improving the performance of NZQA in the conduct of its annual round of national examinations for the NCEA. Just three months earlier, the Government had also released its report on the 2004 Scholarship to the Deputy State Services Commissioner by the Review Team led by Doug Martin (State Services Commission, 2005, A pril), itself only three months after another report prepared by the Scholarship Reference Group for the Associate Minister of Education (Scholarship Reference Group, 2005). There have also been major changes in the structure of the New Zealand Qualifications Authority, with a new Chief Executive Officer starting in May 2006, a new Board chair and three new deputy chief executives (Qualifications, Quality Assurance and Corporate/Strategic) appointed from outside the organisation.

\section{Towards A Framework for Evaluating Qualifications Reforms}

Scrutiny of the NCEA has continued unabated since its implementation. From the public's perspective, it might be concluded that the State Services Commission report of July 2005, was another attempt by the Government to rescue the NCEA and the agency responsible for its implementation. As noted above, this would be overly simplistic, as evaluation of a policy's efficacy is not solely dependent on what the public think of it. A more reasonable evaluation is to examine how well the objectives set for the policy have been met, using multiple sources of information or "evidence". Hence, this article includes reference to the contribution of government reviews, academic research findings and "in-house" reports towards understanding the impact of the NCEA and its value as a national qualification. This enterprise is essential if any conclusions are to be made about the efficacy of the NCEA in particular (and qualifications available to secondary students in general) in terms of meeting the Government's policy objectives. This needs to be taken into account, along with an assessment of its acceptability to students, teachers, parents and the general public as a replacement for the previous system of secondary qualifications.

Investigating whether a reform is achieving its intended purpose requires an evaluation framework that makes explicit the types of information required and ways of interpreting the information. Given that qualifications reforms and associated changes in the certification of secondary students have been moving at a rapid pace in recent years, some possibilities in moving towards what constitutes the most useful 
methodology for evaluating the impact of secondary qualifications reforms are discussed below.

\section{Piloting}

A common strategy is to pilot a new system on a smaller scale to identify conceptual and implementation issues that can then be resolved prior to full-scale implementation. This provides a framework against which the success of the full implementation of the new policy and associated systems can be assessed. Critics of the NCEA have asked why it was not piloted before being implemented. Given the scope of changes to the design of secondary qualifications, initially this appears to be a fair claim. However, while some parts of a national education system can be separately developed and critiqued (such as syllabus documents for a new subject), generally national curricula, or assessment and qualifications systems have some inherent features, such as being closely integrated and/or mutually dependent, which mean that piloting is unlikely to be a feasible option. It is not normally possible to run a pilot of a complete, new national system. It is also difficult to pilot parts of a national qualifications system when all the parts are supposed to be integrated and are based on common principles. In practice, in New Zealand the NQF was developed in a graduated fashion, and the three levels of school qualifications were implemented in a phased way. The intention of the original plan to also include university degrees on the NQF did not occur, as the universities vigorously maintained their independence (Hall, 1995).

\section{Consultation or consensus}

Another strategy is to consult parties likely to be affected by a policy, to determine what needs to change, and ascertain the potential acceptability of different options for reform. During the 1980s and early 1990 s several national consultations were carried out on the need for reform of secondary qualifications (Philips, 1998). However, consultation on the final plan for the NCEA was limited. This is not surprising, as national reforms of secondary certification and qualifications are complex, involving multiple stakeholders, and changes in one area are likely to have both foreseen and unforeseen consequences in other areas. However, at a practical level, while full consultation on such a plan is logistically feasible, political imperatives often assume more importance. Views of stakeholders about intended policies are thus unlikely in themselves to provide useful and valid information about how they might work in practice.

Moreover, there is the question of whose views should be given most weight. It is unlikely that true consensus could be reached amongst all parties: that is, students, teachers, the public, employers and others involved in providing secondary and tertiary education. When the reform affects a large number of stakeholders, everyone has a view, and because a national qualification is at issue, high stakes are involved. Nevertheless, systematic monitoring of issues raised in the media by a range of stakeholders, including particularly vocal interest groups, does provide one way of gathering evidence of the impact of a policy. While stakeholders at all levels of the system will have opinions, in the absence of valid empirical data, selective views may turn out to resist change or to influence the nature of the reform. Ultimately, however, the government, as the primary driver of policy change, has to make decisions about the nature of the those changes and maintain their impetus.

\section{Borrowing}

A third approach is to examine what has happened in other countries, including the findings from evaluations, research studies, and operational reviews. In practice, many policies are developed in this way, as was the case for New Zealand's new system of national qualifications in its first years. Starting in the 1980s, ideas from other countries were "borrowed" to create the national qualifications framework, and then "transmuted" in to a unitary framework unlike any other in the world (Philips, 1998). For evaluative purposes, this is a kind of policy short-cut, as it is presupposed that the types of issues or challenges faced in the system where the policy originated, and the research and other evidence obtained about its implementation, are also likely to be applicable in New Zealand. Generally, however, other countries have tended not to adopt the same radical reform as in this country, preferring instead to take a more cautious "incrementalist" approach, such as within the United Kingdom, and the various states in Australia.

\section{Impact evaluation}

A fourth approach is to analyse the impact of the reform as it is being implemented, or soon after its initial implementation. In the case of a national reform of secondary certification this is likely to be a piecemeal 
and complex exercise taking a number of years. Evaluation needs to be conducted carefully over time. A variety of types of evidence are likely to be required, and the views of different stakeholders sought and represented. It is essential that any evidence gathered on the impact of the reforms is objective and transparent, and meets the tests of rigour. One complication is that small changes may be made to the policy to assist its acceptance or to address issues that have arisen early in the implementation, and these in turn will have an impact on stakeholders' views and behaviour - so it is unlikely that the reform can ever be evaluated in its entirety or at a single point in time.

One essential feature of this type of evaluation is that the policy objectives need to be clearly specified, and information about the success with which these have been achieved needs to be gathered. This is the approach explored in this article, although more extended research is required to determine whether the reforms of secondary certification in New Zealand have achieved the desired policy outcomes, and whether the "policy imperatives" guiding the implementation of the national qualifications framework have been met (Donn \& Davies, 2003). While from the perspective of the policy-makers the policy might be working (because, for example, more students are leaving school with qualifications), from other perspectives the policy may not be regarded as successful. In New Zealand, while the majority of secondary schools offer the NCEA, some schools prefer to offer other qualifications (e.g., the International Baccalaureate or the Cambridge International Examinations) because they believe that the NCEA does not meet their students' needs.

\section{Evaluating the Impact of the NCEA}

Each of the approaches outlined above provides some insight into the development and implementation of educational policies. But none of them is sufficient in itself. In the case of the NCEA, for the reasons given above, a pilot study was not conducted, so information that might have assisted in shaping the final design of the NCEA was not available from this source. Consultation about the proposed NCEA was also restricted and, while a number of features of the NQF were adapted from the examination systems in other countries, such information in itself does not fully explain stakeholders' responses to the NCEA (Philips, 2003). A systematic research programme taking into account the Government's policy objectives for the new national certification system was therefore deemed desirable.
A multi-disciplinary approach has been adopted by the Ministry of Education and the NZQA to carry out an evaluation of whether the NCEA is working well. Since 2002, this approach has involved contracts with the New Zealand Council for Educational Research (e.g., the Learning Curves studies, Hipkins et al., 2002, 2004, 2005) and Victoria University of Wellington, as well as in-house research carried out by staff at NZQA itself. As the NCEA represents government policy, evaluation must of necessity focus on the realisation of the objectives set for it, take place in "real time" and be based on the experiences of learners, teachers and other stakeholders, as well as being evaluated against soundly-based criteria.

A variety of methodologies have been used, and a wide range of different sources have provided information on the impact of the NCEA, and on associated assessment practices in schools. Besides aggregated data analysis, data on student achievement of individual standards, as well as information on the difficulty of each standard and a monitoring of students' results as part of the external assessment process, have been examined. Information from studies of assessment practices within schools (particularly for internally assessed or school-based standards), such as moderation practices, recording and reporting of students' results, and the way in which schools are changing their programme design since the NCEA's introduction, has been gathered. The principal focus is on analysis of comments from surveys and interviews with participants, and a consideration of the impact of NZQA's systems on learner and teacher practice.

Key themes, considered to be fundamental to such an evaluation, relate to standards, assessment, qualifications design, and whether the intent of the policy is realised.

1. As it is a qualification based on assessment against standards, the evaluation must take into account what is known about standards, their design, interpretation and modification.

2. As learners are awarded qualifications based on assessment of their achievement, the evaluation must take into account feedback on the assessment processes used and learners' and teachers' experiences of them.

3. As the qualification is different in many respects from the qualifications that it has replaced, the evaluation must take into account both positive and negative impacts of the design while also acknowledging that "evidence" may beinterpreted in different ways 
- what some may interpret as positive, others may interpret as negative. Government officials, for example, may believe that if some schools offer a range of qualifications to their students, rather than just the NCEA, this indicates a policy failure. On the other hand, some parents and schools may believe that having choice, or a range of available assessment options, is a policy success.

4. As the qualification system has been implemented to address government policy objectives aimed at allowing a more diverse range of students to gain nationally recognised qualifications, for both individual and national social and economic benefit, any evaluation must consider evidence about the extent to which these policy objectives are being met.

\section{Standards}

In a "standards-based" certification system, the definitions of each standard and a shared understanding of their meaning are central. A standard is a shorthand description of the learning or behaviours that need to be demonstrated, and the assessment criteria that will be applied to make this judgement, in order to gain credit towards a national qualification. Clearly issues to do with how a standard is defined and validated, and whether it can be interpreted in a consistent manner by teachers working with learners of different interests, capabilities and achievement, and in different learning contexts, is critical. As noted by Black (2001, p. 5), "It is clear that communication of the meaning of the standards, and so of the criteria that should be the basis of any assessment, is essential. Such communication requires a balance between suitably explicit rule statements, and examples."

When experts in the field define standards of performance, it would seem to be to be a fair assumption that there would be some consensus about their definition and how they should be applied in different educational contexts. However, questions concerning the achievement standards (used for largely "academic" secondary qualifications) have been raised about consistency of definition from one level to the next, and about the terminology that allows discrimination both between levels of achievement within a standard, and also between successive levels in the qualifications framework (Elley, 1995). Professional judgement alone may not be enough without extensive professional development, including the provision of examples to demonstrate the qualities of student work indicating different levels of achievement (exemplars). Although the standards are reviewed every three years in order to maintain consistency, and changes are often minor, occasionally some standards are redefined, as a result of feedback from teachers and others. However, with regard to externally assessed standards, annual feedback after the end of the examination cycle suggests that the difficulty of the examinations is reasonably consistent from year to year (Research, Monitoring and Analysis, 2006b).

When there are have different standards (or types of standards) for different areas of learning - as with the achievement standards and unit standards in New Zealand - inevitably the issue of parity of esteem between the academic and vocational is raised. This was also noted by Black (2001, pp. 7-8). While this has to some extent been less of a focus in New Zealand than it has been in some other countries, recent findings have indicated that it is a concern for some teachers and students. For example, some students consulted about the NCEA indicated that they believed that unit standards are inferior to achievement standards because the students gaining most credits from unit standards tended to be among the lower performing students (Research, Monitoring and Analysis, 2006a). Some teachers have also expressed the same views (Hipkins et al., 2005; Alison, 2005).

\section{Assessment}

Black also commented that the implementation of the NCEA would inevitably raise issues about validity, reliability, and manageability (2001, pp. 9-15). Other New Zealand commentators reached similar conclusions before the NCEA was implemented (Hall, 2001). The importance of assessment issues in the Scottish examinations debacle has also been explored (Raffe et al., 2002). An earlier paper has discussed in more detail some of the views expressed by students and teachers about assessment within a standards-based system (Philips, 2006).

Some of the key issues are:

(a) Differences between internally and externally assessed standards: Evidence from several studies suggests that many students prefer internal assessment, although they tend to believe that results from external assessments are of more value (Hipkins et al., 2005; Research, Monitoring and Analysis, 2006a; Meyer et al., 2006);

(b) Concerns about the consistency of results from year to year: The State Services Commission review noted concerns expressed by the public, teachers and students about the differences in the proportions of students gaining the Not Achieved, Achieved, Merit and Excellence results in some standards between 2003 and 2004. As 
a result, new systems were developed in 2005 to monitor the results as they were being marked, with changes made to a small number of marking schedules (17 out of approximately 330 );

(c) The quality and consistency of external moderation of internally assessed standards: Concerns have been raised about the inconsistency of moderators' judgements with regard to the quality of assessment tasks and the grading of examples of students' work, which schools are required to submit every year for predetermined standards (Alison, 2005);

(d) The need to have three successive years of external assessment: Such examinations in the final three years of secondary school, although a feature of the New Zealand system for many decades, are a feature of very few other systems.

Thus far much of the evidence about the impact of the new qualifications system has been based on reports in the media, feedback provided at various national meetings of those involved with secondary education, and occasional surveys. However, NZQA is also conducting a more in-depth study of how 60 teachers have changed their assessment practices since the implementation of Level 3 NCEA (for the first time in 2004). This has involved the collection of interview and other data from the participating teachers in 2004, 2005 and 2006. Reports on this study, Assessment Practices of Year 13 Teachers, are currently being prepared. It is anticipated that this study will be the first to demonstrate what changes teachers in four specific subjects have actually made, and the reasons for these changes.

\section{Qualifications design}

The most appropriate design for secondary qualifications or certification in New Zealand has been on the national policy agenda for well over two decades (Committee of Inquiry Into Curriculum, Assessment and Qualifications in Forms 5 to 7, 1986; Allen et al., 1997). Design issues have also been part of the discussion being held on a regular basis by members of the Secondary Principals' and Leaders' Forum, a national advisory group chaired jointly by the Secretary for Education and the Chief Executive of NZQA. Education officials meet regularly to discuss the implementation of the national secondary qualifications system, and indicate where possible enhancements can be made. At this stage it is not expected that there will be a large-scale review of the system, as it needs several more years to become properly established.
Despite this, some educators have advocated that changes be made to some aspects of the NCEA: for example, to improve teacher professional judgement and system credibility (Alison, 2005), to improve the quality of assessment (State Services Commission, 2005), to create larger components than unit or achievement standards to improve coherence in teaching and learning programmes (Hall, 2005), and to increase student motivation (Meyer et al., 2006). This latter study summarised students' concerns about the design of the NCEA and the way this impacted on their motivation. Some students, for example, reported that there was little motivation to aim for "merit" and "excellent" performance when the system did not allow for the award of extra credits for achievement at these levels. These concerns were also raised in other studies (Alison, 2005; Research, Monitoring and Analysis, 2006a). Alison's study also reported that many teachers acknowledged the need for careful management of further opportunities for assessment, and argued that external moderation of internally assessed standards should be enhanced.

One of the purposes of the current design of secondary qualifications in New Zealand is to integrate them within the broader $\mathrm{NQF}$, on the basis that secondary qualifications should not be seen in isolation from other qualifications. So it is not just a question of whether the school qualifications are linked to the national curriculum (or alternatives), but of how well they lead into further learning, including learning in tertiary institutions and/or the workplace. There is a strong argument that they should be closely linked with, and provide a pathway into, post-school qualifications in a "seamless" way. This is true whether they are primarily academic (associated with continuing study at university) or vocational (associated with qualifications required for participation in the workforce, such as industry or service occupations), or simply for lifelong learning, broadly defined. The best way to achieve this policy goal is seen to be through an integrated or unitary system, which minimises differences rather than exaggerates them, and is based on a common set of design principles such as standards and credits, defined achievement levels, and quality assurance criteria. However, this goal has not yet been achieved.

\section{Policy objectives}

Donn and Davies (2003) noted that national qualifications frameworks are designed to meet a range of policy imperatives. Key among these in New Zealand (and elsewhere) are the notions of encouraging a larger 
number of learners to remain engaged in learning for longer, to have a wider range of learning achievements appropriately recognised, and to have a broader number of pathways available to them so that they are not locked into a small number of tightly defined tracks or streams.

There is some positive evidence that in New Zealand more students are now staying involved in post-compulsory education and training, and it is expected that this trend will continue (Ministry of Education, 2005). It appears, too, that more Pasifika and Maori students are gaining qualifications. There is also some evidence that many secondary schools are offering their students increased opportunities to gain a wider range of qualifications, through alternative pathways (Pilcher \& Philips, 2007). Some secondary schools are being innovative in the ways they design their teaching and learning programmes for different student needs, thus facilitating entry to different forms of further education and training, employment, and lifelong learning (Pilcher, 2006a, 2006b).

\section{Conclusions}

Evaluating the impact and overall effectiveness of a national policy one that could affect everyone in the country - is complex. Potentially, there is a huge body of evidence related to features of secondary qualifications and certification, and its impact on different stakeholders; however, the evidence can be interpreted in different ways. Issues remain about the appropriateness of the specification of standards, the defining characteristics of different levels of achievement, and the comparability of results from internally and externally assessed student work. There is now increased acceptance of: the reliability of externally assessed results, due to enhanced monitoring procedures; the value of certification of a broader range of achievements; and the need for minor progressive enhancements to the senior secondary qualifications system rather than wholesale change.

At the end of May 2007, as this article was going to press, the Minister of Education, the Hon Steve Maharey, made an announcement about ongoing improvements to the NCEA. He noted that officials from both the Ministry of Education and NZQA had now evaluated recommendations from recent reviews of the NCEA. In keeping with some of the findings referred to in this article, the specific areas of improvement included the endorsement of NCEA Level 1, 2 and 3 certificates, recognition of students' overall achievement within subjects, the reporting of "not achieved" results for internally assessed standards, and additional moderation of internally assessed standards.
While these changes could be interpreted by many critics of the NCEA as minor adjustments, analysis of the research carried out to date suggests that they are well-founded in the reported views and experiences of stakeholders. Indeed, I would argue that policy changes such as these indicate the significance of the ongoing research programme in identifying potential improvements to the NCEA, and a justification of the contribution of the growing body of solid research evidence to national policy development in assessment.

\section{References}

Australian Council for Educational Research. (2006). Australian Certificate of Education: Exploring a way forward. Australian Government, Department of Education, Science and Training.

Allen, P., Crooks, T., Hearn, S., \& Irwin, K. (1997). Te Tiro Hou: Report of the Qualifications Framework Inquiry. Report commissioned by the New Zealand Post-Primary Teachers' Association. Wellington: PPTA.

Alison, J. (2005). Teachers talk about NCEA. Wellington: PPTA.

Black, P. (2001). Report to the Qualifications Development Group (QDG), Ministry of Education, New Zealand on the proposals for the development of the NCEA. Wellington: Ministry of Education <www.minedu.govt.nz/ web/downloadable/d15591_v1/Paul\%20Black\%20report.pdf $>$

Coles, M. (2006). A review of international and national developments in the use of qualifications frameworks. Turin: European Training Foundation. $<$ www.etf.europa.eu/web.nsf/Pages/Related+Publications? OpenDocument\&c=\&EMB =/pubmgmt.nsf/(WebByCountry Theme)?OpenView\&RestrictToCategory=Qualification frameworks \&Expand $=1 \& \mathrm{LAN}=\mathrm{EN}$ ? Opendocument $>$

Committee of Inquiry Into Curriculum, Assessment and Qualifications in Forms 5 to 7. (1986). Learning and achieving. Wellington: Department of Education.

Donn, G., \& Davies, T. (Eds). (2003). Promises and problems for Commonwealth qualification frameworks. A report of a Commonwealth Seminar held in Wellington, New Zealand, February. London: Commonwealth Secretariat. 
Elley, W. B. (1995). What is wrong with standards based assessment? In R. Peddie \& B. Tuck (Eds.), Setting the standards: Issues in assessment for national qualifications (pp. 78-98). Palmerston North: Dunmore Press.

Hall, C. (1995). University qualifications and the New Zealand National Qualifications Framework: Obstacles and a way forward. In R. Peddie \& B. Tuck (Eds.), Setting the standards: Issues in assessment for national qualifications (pp. 154-176). Palmerston North: Dunmore Press.

Hall, C. (2000). National Certificate of Educational Achievement: Issues of reliability, validity and manageability. New Zealand Annual Review of Education, 9, 173-196.

Hall, C. (2005). The National Certificate of Educational Achievement (NCEA): Is there a Third Way? In J. Codd \& K. Sullivan (Eds.), Education policy directions in Aotearoa New Zealand (pp. 235-265). Southbank, Victoria: Thomson/Dunmore Press.

Hipkins, R., \& Vaughan, K. (2002). Learning Curves: Meeting student needs in an evolving qualifications regime. From cabbages to kings: A first report. Wellington: New Zealand Council for Educational Research.

Hipkins, R., Vaughan, K., Beals, F., \& Ferral, H. (2004). Learning Curves: Meeting student needs in an evolving qualifications regime. Shared pathways and multiple tracks: A second report. Wellington: New Zealand Council for Educational Research.

Hipkins, R., Vaughan, K., Beals, F., Ferral, H., \& Gardiner, B. (2005). Shaping our Futures: Meeting secondary students' learning needs in a time of evolving qualifications. Final report of the Learning Curves project. Wellington: New Zealand Council for Educational Research.

Lee, H., \& Lee, G. (2001). The National Certificate of Educational Achievement (NCEA): "Fragile - handle with care". New Zealand Annual Review of Education, 10, 5-38.

Meyer, L., McClure, J., Walkey, F., McKenzie, L., \& Weir, K. (2006). The impact of the NCEA on student motivation. Report submitted to the Ministry of Education. Wellington: College of Education and School of Psychology, Victoria University of Wellington.

Ministry of Education. (2005). New Zealand schools/Nga Kura Kaupapa o Aotearoa: Report on the compulsory school sector. Wellington: Ministry of Education.
Philips, D. (1998). The switchmen of history: The development of a unitary qualifications framework. Unpublished PhD Thesis, Victoria University of Wellington.

Philips, D. (2003). Lessons from New Zealand's National Qualifications Framework. Journal of Education and Work, 16(3), 289-303.

Philips, D. (2005). The policy process and policy on policy-making. In J. Codd and K. Sullivan (Eds.), Education policy directions in Aotearoa New Zealand (pp. 127-140). Southbank, Victoria: Thomson/Dunmore Press.

Philips, D. (2006). Teachers' and students' experiences of standards-based assessment in New Zealand. Paper presented at the 32nd annual conference of the International Association for Educational Assessment, Singapore, May 21-26.

Pilcher, E. (2006a). Changing Courses: National survey. A study of schools' responsiveness to the National Qualifications Framework. Wellington: New Zealand Qualifications Authority.

Pilcher, E. (2006b). Changing Courses: Preliminary investigation. A study of schools' use of the NQF to improve educational pathways. Wellington: New Zealand Qualifications Authority.

Pilcher, E., \& Philips, D. (2007). New Zealand Annual Review of Education, 16, 151-171.

Raffe, D., Howieson, C., \& Tinklin, T. (2002). The Scottish educational crisis of 2000: An analysis of the policy process of unification. Journal of Education Policy, 17(2), 167-185.

Raffe, D. (2005). Qualifications frameworks in Europe: Learning across boundaries. Report of the Glasgow Conference, September, 22-23. Edinburgh: Scottish Executive.

Research, Monitoring and Analysis. (2006a). Student Views of the NQF and NCEA: Research report on focus groups with Year 12 and Year 13 students. Wellington: New Zealand Qualifications Authority.

Research, Monitoring and Analysis. (2006b). 2005 Teachers' survey of the externally assessed standards. Wellington: New Zealand Qualifications Authority.

Scholarship Reference Group. (2005, March). Report of the Scholarship Reference Group. Prepared for the Associate Minister of Education. Wellington: Ministry of Education. 
State Services Commission. (2005, April). Report on the 2004 Scholarship to the Deputy State Services Commissioner, by the review team led by Doug Martin. Wellington: New Zealand Government.

State Services Commission. (2005, July). Report on the performance of the New Zealand Qualifications Authority in the delivery of secondary school qualifications, by the review team led by Doug Martin. Wellington: New Zealand Government.

Strachan, J. (2002). Assessment in change: Some reflections on the local and international background to the National Certificate of Educational Achievement (NCEA). New Zealand Annual Review of Education, 11, 245-273.

Whitty, G. (2006). Education(al) research and education policy making: Is conflict inevitable? British Educational Research Journal, 32(2), 159-176.

Young, M. (2005). National qualifications frameworks: Their feasibility for effective implementation in developing countries. Geneva: International Labour Office.

Zepke, N., Leach, L., Brandon, J., Chapman, J., Neutze, G., Rawlins, P., \& Scott, A. (2006) Standards-based assessment in the senior secondary school: A research synthesis. Wellington: New Zealand Qualifications Authority.

\section{The author}

Dr David Philips is the General Manager, Assessment and Reporting Branch of the Victorian Curriculum and Assessment Authority in Melbourne. Previously he was the Manager, Research and Knowledge Services at the New Zealand Qualifications Authority, where he worked between April 2002 and January 2007, after periods at the Ministry of Education, the Education Review Office and the New Zealand Council for Educational Research. His PhD in educational policy was on the development of the National Qualifications Framework. 